\title{
LETTERS
}

\section{The authors respond to "The future of colorectal cancer screening: Parentalism or shared decision-making?"}

We respectfully object to the interpretation ${ }^{1}$ of our commentary ${ }^{2}$ as one that would promote withholding information from screening participants. We essentially sought to express concerns about the proposed guideline because it entailed serious limitations, on multiple levels, best described by the authors themselves as follows:

The process of making these recommendations was challenging, often with opposing views in the panel. Particular challenges were the lack of randomised trials for colonoscopy and FIT [fecal immunochemical test] (which made us rely on modelled estimates of low certainty for screening benefit) and the uncertainty in people's values and preferences. ${ }^{3}$

We stand by our assertion that this guideline project lacks the credibility to justify a drastic change in the philosophy of colorectal cancer screening in the face of robust evidence for the efficacy of organized screening.

\section{Barbara Bielawska MD MSc}

Gastroenterologist, University of Ottawa, Ottawa, Ont.

\section{Catherine Dubé MD MSc}

Gastroenterologist, University of Ottawa, Ottawa, Ont.; and Cancer Care Ontario, Toronto, Ont.

Cite as: CMAJ 2020 May 4;192:E485. doi: 10.1503/cmaj.74963

\section{References}

1. Bretthauer M, Helsingen LM, Kalager M, et al. The future of colorectal cancer screening: Parentalism or shared decision-making? [letter] CMAJ 2020;192:E484.

2. Bielawska B, Dubé C. Colorectal cancer screening: It is not time for a radical shift. CMAJ 2020; 192:E51-2.

3. Helsingen LM, Vandvik PO, Jodal HC, et al. Colorectal cancer screening with faecal immunochemical testing, sigmoidoscopy or colonoscopy: a clinical practice guideline. BMJ 2019;367: 15515.

Competing interests: Catherine Dubé is contracted by Ontario Health (Cancer Care Ontario) for the role of clinical lead for the ColonCancerCheck program, Ontario's colorectal cancer screening program. No other competing interests were declared. 